\title{
CAMBIO CULTURAL Y LECTURA. HACIA UNA NUEVA CULTURA LEC- TORA
}

Resumen. Las limitaciones de las prácticas lectoras actuales quizás puedan apreciarse mejor en el seno de los cambios culturales que se producen con el paso de la sociedad moderna a la posmoderna. Estas tecnologías de la vida cotidiana están cambiando profundamente nuestras formas de trabajar, de relacionarnos, de vivir. La sacralización del libro propia de la modernidad pierde sentido en el mundo audiovisual actual, donde multitud de jóvenes descifran reglas y desarrollan nuevas destrezas usando los nuevos artefactos tecnológicos. La ignorancia de la vigencia de las nuevas prácticas culturales conduce al desencuentro cultural intergeneracional, que tanto daño está causando en los sistemas escolares. Las condiciones de las sociedades de la información reclaman un nuevo contexto para la cultura lectora, emergiendo nuevas posibilidades formativas.

Palabras clave: Lectura, cambio cultural, tecnologías de la vida cotidiana, innovación educativa, formación del lector.

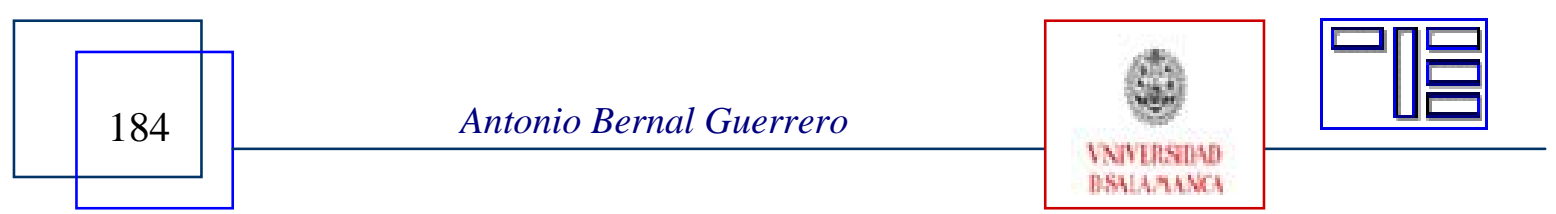




\begin{tabular}{|c|c|c|}
\hline ロ包 & $\begin{array}{l}\text { Revista Electrónica } \\
\text { Educación y Cultura en l }\end{array}$ & $\begin{array}{l}\text { Educación. } \\
\text { e la Información. }\end{array}$ \\
\hline & http://www.usal.es/teoriaeducacion & Vol. 9. $N^{\circ}$ 3. Noviembre 2008 \\
\hline
\end{tabular}

\title{
CULTURAL CHANGE AND READING. HEADING TOWARDS A NEW READ- ING CULTURE
}

\begin{abstract}
The current limitations to the reading practices can probably best be appreciated within the cultural changes coinciding with the step from a modern society to a post modern one. These technologies of daily life are changing the way we work, we interact and we live. The sacralisation of the book -characteristic of modernity- is totally lacking sense in the current audiovisual world, where millions of youngsters decipher rules and develop new abilities using new technological devices. Ignoring the new cultural practices simply leads to cultural misunderstandings between generations, which are causing so much harm to the scholar system. The conditions in the information societies are calling for a new context for the culture of reading, which will bring up new educational chances.
\end{abstract}

Key words: Reading, cultural change, daily life technologies, educative innovation, education of the reader.

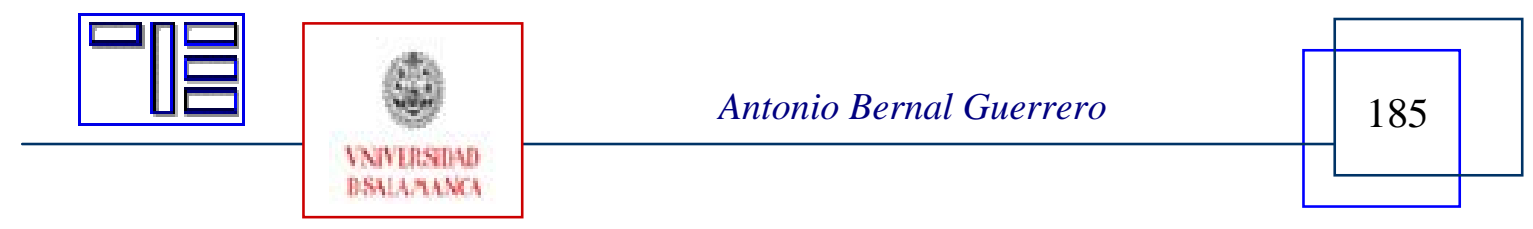




\section{CHANGEMENT CULTUREL ET LECTURE. VERS UNE NOUVELLE CUL- TURE DE LECTURE}

Sommaire: Les limitations des pratiques de lecture actuelles peuvent peut-être mieux s'apprécier au sein des changements culturels qui se produisent lors du passage de la société moderne à la société post-moderne. Ces technologies de la vie quotidienne sont en train de changer profondément nos manières de travailler, d'établir des rapports, de vivre. La sacralisation du livre, propre à la modernité, perd tout son sens dans le monde audiovisuel actuel, où une foule de jeunes déchiffrent des règles et développent de nouvelles compétences en se servant des nouveaux appareils technologiques. Ignorer la présence des nouvelles pratiques culturelles conduit à l'incompréhension culturelle intergénérationnelle, source de tant de dégâts dans les systèmes scolaires. Les conditions des sociétés de l'information exigent un nouveau contexte pour la culture de la lecture, et de nouvelles possibilités émergent quant à la formation.

Mots clés: Lecture, changement culturel, technologies de la vie quotidienne, innovation éducative, formation du lecteur.

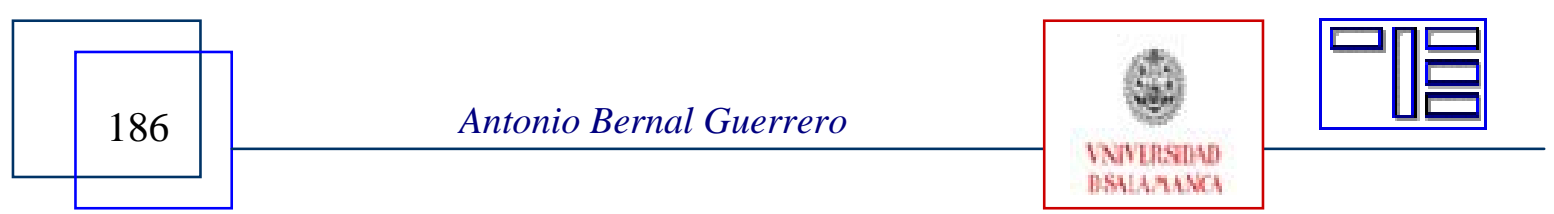




\begin{tabular}{|c|c|c|}
\hline 밈ㅁㅁㅁㅁ & $\begin{array}{l}\text { Revista Electrónic } \\
\text { Educación y Cultura en }\end{array}$ & $\begin{array}{l}\text { Educación. } \\
\text { e la Información. }\end{array}$ \\
\hline & http://www.usal.es/teoriaeducacion & Vol. 9. $N^{\circ}$ 3. Noviembre 2008 \\
\hline
\end{tabular}

\title{
CAMBIO CULTURAL Y LECTURA. HACIA UNA NUEVA CULTURA LECTORA
}

\author{
Antonio Bernal Guerrero \\ abernal@us.es \\ Universidad de Sevilla
}

Tal vez sin el protagonismo tradicional, la lectura sigue y seguirá siendo necesaria en las sociedades de la información, aunque con un considerable cambio respecto al pasado. Incluso, puede afirmarse que la lectura crítica se hace más necesaria que nunca ante las múltiples amenazas que nos acechan en la sociedad globalizada. Adviértase, junto al peligro de las nuevas desigualdades originadas en el acceso a la cultura, la amenaza de que la información, gracias a la multiplicidad de fuentes informativas -piénsese que, en poco tiempo, habrá una generación de personas cuyos conocimientos del mundo se habrán conseguido, en gran medida, mediante los buscadores de Internet más conocidos, convirtiéndose a menudo en la única vía de "acceso al conocimiento"-, se acumule desprovista de significado, de sentido crítico, aumentando el riesgo de que quede dañada seriamente la comprensión del mundo y, con ella, la autonomía posible de las personas. La lectura como práctica de incorporación cultural, si bien originariamente tuvo un carácter iniciático y minoritario, hoy se considera un bien digno de hacerse extensivo a todos los seres humanos. El valor instrumental de la lectura en la vida de las personas para desarrollar y lograr sus metas, así como para poder participar en la sociedad, la convierte en una condición de la ciudadanía y de la integración social. No hará falta insistir en el poder nivelador social de la lectura, que puede llegar a ser tan revolucionario como la redistribución de la riqueza, puesto que permite la redistribución de la cultura. Con sus estudios sobre la relación entre el lenguaje y la situación económica y cultural, Bruner (2001) lo ha puesto sobradamente de manifiesto.

Sin embargo, pese a las bondades que se advierten en la lectura, se han producido cambios importantes de distinto signo que cuestionan la tradicional cultura de la lectura, de la que acaso esté emergiendo una nueva cultura lectora. El irrefragable lenguaje de los hechos nos dice que se lee poco; según el Barómetro de Hábitos de Lectura y Compra de Libros 2008 realizado por Conecta Research \& Consulting para la Federación de Gremios de Editores de España, casi la mitad de los españoles mayores de 14 años, el 44.7\%, no había leído un libro en el primer trimestre de este año, confirmándose en

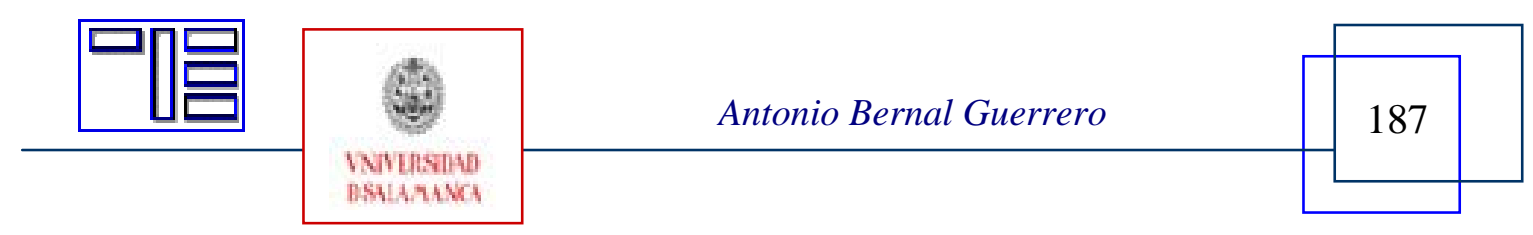


líneas generales los resultados que arrojó el estudio sobre hábitos de lectura realizado en 2002 por el Centro de Investigación y Documentación Educativa del Ministerio de Educación, en el que se indicaba que el porcentaje de adultos que no leía nunca o casi nunca era del $45 \%$, que el $26 \%$ de adolescentes españoles podía considerarse "no-lectores" y el $38 \%$ de ellos "lectores ocasionales". Se habla de "crisis" de la lectura ${ }^{1}$ y para tratar de explicarla se dan argumentaciones más amplias o generales, como por ejemplo el peso del utilitarismo en el currículum, o más específicas, como el número de horas de enseñanza de la asignatura de Lengua, o de Lengua y Literatura... El escaso éxito de las prácticas lectoras actuales tal vez pueda apreciarse mejor en el seno de los cambios culturales que se producen con el paso de la sociedad moderna a la posmoderna. Las prácticas de lectura en los sistemas educativos actuales obedecen, por lo general, a un proyecto cultural ilustrado que se ideó en otra época para otra sociedad. En la era de la información, dichas prácticas sencillamente están descontextualizadas, dramáticamente alejadas del mundo real y virtual que experimentamos. Es preciso analizar los nuevos marcos culturales en las sociedades de la información.

Posiblemente, los medios de comunicación de masas junto a la propia sociedad de masas nos hayan enseñado más sobre la cultura real que el criterio y juicio de las elites. En la sociedad de consumo se produce una cultura antagónica a la del cenáculo. La cultura, dentro de la sociedad de masas, no es algo sagrado sino popular, no es algo ubicado en las alturas sino próximo y al servicio del bienestar propincuo. Los que hemos sido formados fundamentalmente en la tradición escrita seguimos aplicando códigos literarios y filosóficos para interpretar todas las creaciones culturales. Mientras, el canon de la imagen y el sonido es aplicado con naturalidad por las nuevas generaciones que han crecido y crecen al amparo predominante de las tradiciones visual y digital (Marinoff, 2006). Si los valores del capitalismo de producción señalaban con claridad la diferencia entre lo bello y lo feo, entre lo bueno y lo malo, entre un género y otro, en el capitalismo de ficción, de consumo, en la sociedad de la información, las categorías se diluyen sobre el vasto espacio planetario. Frente a la magnanimidad, la grandilocuencia, el orden inculcado por la Ilustración y continuado por el capitalismo de producción, los objetos de ahora cada vez ocupan menos espacio, son más livianos y su coste es progresivamente decreciente. "En la organización de sistemas, la retícula sustituye a la pirámide, la construcción virtual al monumento y la intangibilidad de Internet al lomo del libro" (Verdú, 2005, 24). Frente a una cultura tradicional básicamente accesible al sentido del tacto, la cultura de ahora radica en la transparencia y el placer de las superficies.

\section{1.- SOCIEDAD DE LA INFORMACIÓN Y CULTURA DE SIMULACIÓN}

Las nuevas tecnologías que constituyen el denominado ciberespacio están impactando hondamente en nuestra sociedad. No se trata de un mero progreso tecnológico, de una simple prolongación de los prodigios técnicos de la modernidad sin solución de continuidad. Estas tecnologías están cambiando profundamente nuestras formas de trabajar, de relacionarnos, de vivir. La propia evolución de los ordenadores puede servirnos de hilo conductor para comprender el tránsito de una cultura moderna a una cultura pos-

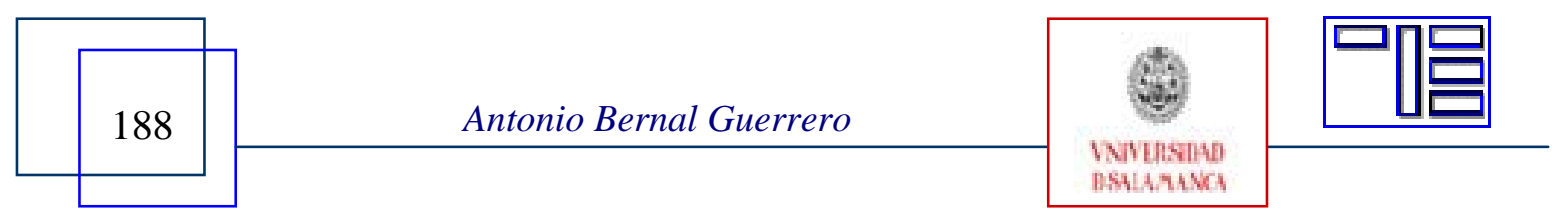


moderna, de una cultura de producción a una cultura de consumo, de una cultura de cálculo a una cultura de simulación.

Hasta no hace mucho era lugar común pensar en los ordenadores como colosales calculadoras. Poderosísimas máquinas que nos impelían a pensar en la cultura informática como cultura de cálculo. Esta imagen no se adapta a las circunstancias y movimientos de la sociedad y la cultura de nuestros días. No es que haya desaparecido su poder de cálculo, se trata más bien de que el interés que despierta el ordenador gira en torno a la navegación, la interacción y la simulación. Progresivamente, la consideración de la interfaz como un mundo en sí mismo se ha ido imponiendo, adquiriendo un creciente protagonismo la cultura informática como cultura de simulación. Los usuarios de ordenadores hoy emplean productos que les permiten manipular sus escritorios simulados, realizar diseños gráficos, dibujar y decorar simuladamente... En múltiples dominios ha ido emergiendo esta cultura de la simulación, que está incidiendo en la comprensión de nosotros mismos, enlazando a millones de personas en nuevos espacios que están alterando nuestro modo de pensar, las formas de relacionarnos, la configuración de nuestras comunidades, nuestras identidades. Hace tres décadas, generalizadamente, los modelos computacionales de la mente eran claramente modernistas, prácticamente todos intentaban describir la mente en términos de estructuras centralizadas y reglas programadas. En cambio, los modelos actuales frecuentemente se abren a la complejidad y el descentramiento. Si en la cultura moderna del cálculo sólo se pensaba en que los ordenadores eran capaces de proyectar y aumentar la inteligencia humana, en la cultura de la simulación se aprecia cada vez más nítidamente que las máquinas podrían ampliar la presencia física de la persona. Conforme se incrementan las interrelaciones de las personas con la tecnología y con otras personas mediante la tecnología, las viejas diferencias entre lo específicamente humano y lo específicamente tecnológico se tornan más complejas. Posiblemente, con el paso de una cultura del cálculo hacia una cultura de la simulación se han producido cambios no únicamente en lo que la máquina hace "para" nosotros, sino también en lo que hace "con" nosotros en nuestras relaciones y nuestros modos de pensar.

Se ha pasado de una estética tecnológica moderna a una estética posmoderna: "nos estamos trasladando de una cultura modernista del cálculo a una cultura posmoderna de la simulación” (Turkle, 1997, 29). La estética de la simulación, introducida al principio por Macintosh, ha pasado a convertirse industrialmente en algo estandarizado: la mayoría de los ordenadores personales que se venden son máquinas MS-DOS con una interfaz icónica Windows. Progresivamente, nos hemos ido adaptando a navegar por simulaciones de pantalla, despreocupándonos de qué es lo que ocurre realmente en el interior de los ordenadores, de qué es aquello que los hace funcionar. En los últimos años, tanto en el lenguaje popular como en el informático, ha ido ganando terreno claramente la cultura de la simulación frente a la cultura del cálculo, cambiando el significado mismo de lo que llamamos "transparencia”. Si hace un par de décadas se entendía por transparencia el poder ver cómo funciona el ordenador interiormente, esto es, conocer completamente

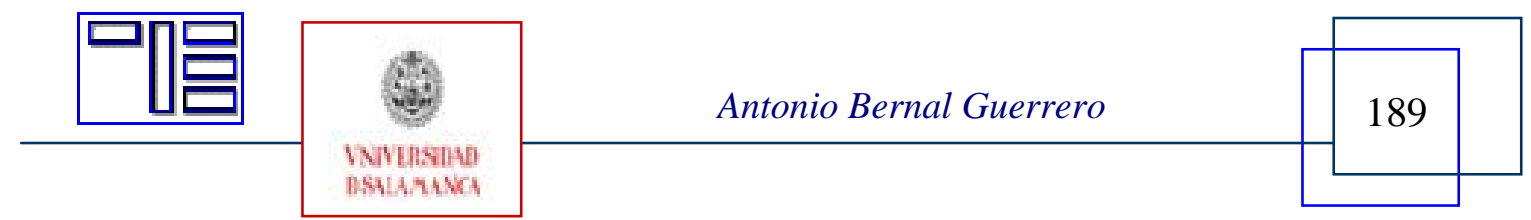


su estructura y procesos subyacentes, actualmente, en cambio, la transparencia hace referencia a la facilidad con la que el usuario puede hacer funcionar al ordenador.

Nuestro mundo es muy complejo, acaso excesivamente complejo para nuestra mente, demasiado complejo para elaborar un constructo mental sobre él desde los principios primarios. Tal vez los ordenadores, a través de la simulación, nos muestren otro camino para su comprensión. Una ingente cantidad de fenómenos complejos dificulta enormemente la comprensión del comportamiento del mundo real desde los primeros principios. Sin embargo, la potencialidad de la simulación informática nos sugiere la comprensión de los fenómenos complejos prescindiendo de sus principios primarios, apropiándonos de ellos mediante la simulación, a través del juego. "No hay una cadena causal simple. Construimos nuestras tecnologías, y nuestras tecnologías nos construyen a nosotros en nuestros tiempos. Nuestros tiempos nos hacen, nosotros hacemos nuestras máquinas, nuestras máquinas hacen nuestros tiempos” (Turkle, 1997, 60-61).

\section{2.- TECNOLOGÍA Y CAMBIO CULTURAL}

Las tecnologías de la vida cotidiana cambian nuestra forma de ver el mundo. La fotografía y el vídeo, en la medida en que se han adueñado de la naturaleza, se han convertido en mediadores de nuestra experiencia como seres humanos, no pocos acontecimientos son desplazados en sí mismos por las grabaciones fijas o móviles que tenemos de ellos. La tecnología del libro también nos modificó terminantemente: a muchos de nosotros se nos hace imposible una visión "limpia” de los paisajes castellano-manchegos, inevitablemente se nos viene a la mente la prodigiosa creación cervantina de don Quijote y sus interpretaciones del mundo. Otros no podrán contemplar un luminoso día de playa sino a través de los ojos de Sorolla, gracias a la extraordinaria apropiación de la naturaleza que la pintura supuso. Los ordenadores también cambian nuestra manera de ver el mundo y con ellos podemos construir cosas de un modo distinto. Con los ordenadores podemos simular la naturaleza o bien crear nuevas naturalezas sin mayor limitación que nuestra propia imaginación, nuestra capacidad de abstracción. El ordenador permite la manipulación, la combinación de elementos, la recombinación. Los signos tomados de la realidad sustituyen a lo real, pero ahora con una novedad: la línea entre las cosas y sus representaciones se ha quebrado, puesto que es posible la representación en ausencia de la cosa real. Con el predominio de una cultura de la simulación, parece advertirse que la gente progresivamente se siente más cómoda con la sustitución de la realidad por sus representaciones. ¿Es menos real un escritorio en una pantalla, donde archivamos nuestra correspondencia, facturas, trabajos y documentos virtuales, que un mueble de escritorio?, ¿acaso nuestras vinculaciones a una comunidad virtual son menos válidas que a otras comunidades en las que estamos presentes físicamente? No tenemos sentido alguno de irrealidad en nuestra comunicación mediada por el ordenador 0 en la relación con los objetos virtuales que nos ofrece. Hemos ido aprendiendo a apreciar las cosas según el valor de la interfaz; en la cultura de la simulación, si las cosas funcionan, se entiende que tienen la realidad necesaria. Ahora es posible, merced a las potencialidades de las nuevas tecnologías, la copia de cosas que no tienen originales. Es

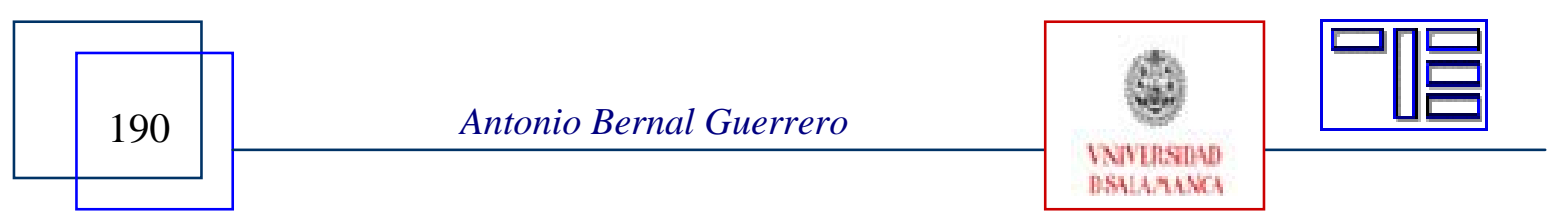


el simulacro al que se refirió Jean Baudrillard (1984). Mundos sin orígenes, diríamos en clave posmodernista.

Portadores de nuevas formas de conocimiento, los ordenadores han pasado a ser fundamentales objetos de pensamiento en la posmodernidad. El estilo Macintosh de las interfaces de ordenador ha servido como soporte de un modo de conocimiento dependiente de la simulación y de la superficie de representación, conforme a una estética tecnológica posmoderna. Las ideas que recogen la imaginación de la cultura extensamente, las teorías apropiables, propenden a ser las que permiten que las personas puedan implicarse activamente. Son teorías con las que se puede jugar. Cuando estas ideas, realmente teorías de la apropiación cultural, van acompañadas de sus propios objetos de modo que las transfieran a otros ámbitos, que las ayuden a expandirse, se potencia su apropiabilidad cultural. Piénsese, por ejemplo, en la apropiación popular de las ideas psicoanalíticas, sin apenas relación con su validez científica, explicable por el vigor de los “objetos” que ofrecía para pensar, ideas casi palpables como los sueños o los actos fallidos. La posibilidad de jugar con estos “objetos” por parte de la gente fue naturalizando la aceptación de la existencia del inconsciente, incluso para millones de personas que nunca han leído una sola línea de la obra del genial Freud y que nunca han visitado el diván de psicoanalista alguno. Si la apropiación cultural se produce a través de la manipulación de objetos específicos, como parece mostrar la historia de las ideas, puede pensarse que el poder de seducción de tales objetos es decisivo para dicha apropiación. Los ordenadores son objetos culturalmente muy poderosos porque seducen a la gente. Seducen las máquinas porque pueden engendrar cierta pasión por ellas, seducen las ideas vehiculadas y generadas a través de ellas porque permiten la interacción, la navegación y la simulación, mas allá de considerarlas productos instrumetalmente útiles. Cuando adquirimos un ordenador no compramos sólo un artefacto útil, un valioso instrumento, sino que desde que lo empezamos a utilizar iniciamos una interacción cotidiana con esa máquina que nos proporciona un nuevo modo de pensar y nos abre expectativas sobre nuestras relaciones con ella. Cuando tenemos la posibilidad de navegar por el ciberespacio podemos acceder a más información y a otras personas, pero también nos podemos ver envueltos en juegos de simulación en los que desempeñamos roles diferentes, donde el yo se torna múltiple, fragmentado, poniéndose de manifiesto a través de los objetos más persuasivos de la nueva cultura informática la crisis de la identidad del sujeto actual.

La cultura informática del cálculo posee una interpretación modernista de la comprensión: es posible reducir las cosas complejas a elementos más simples, es posible comprender desvelando los mecanismos ocultos al funcionamiento de las cosas. La vertiente utópica de la teoría modernista, basada en el análisis y el conocimiento, iba más allá de la mera comprensión de objetos, aspiraba al completo conocimiento del yo y de la sociedad. Las interpretaciones de la sociedad, de la economía, de la política, del hombre mismo, de Marx, de Smith, de Darwin o de Freud son un claro exponente de esta perspectiva modernista, claramente representativas de las "epistemologías de la profundidad”, en palabras de ese vigoroso teórico del posmodernismo que es Fredric Jameson.

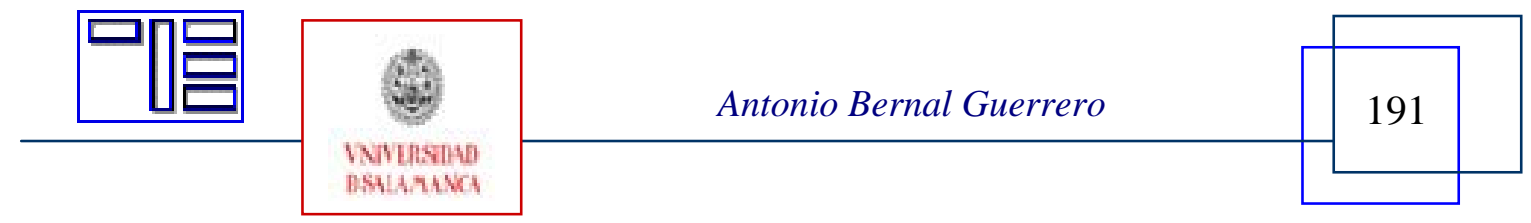


Cuando Jameson (1995) se preguntó sobre el significado del posmodernismo se apercibió de que a la era posmoderna le faltaban objetos para poder representarla. Para imaginar la naturaleza de la modernidad industrial había poderosos objetos: las columnas de humos de las fábricas, las tuberías, la turbina... Pero la posmodernidad, caracterizada por la preferencia de la superficie sobre la profundidad, del juego antes que de la seriedad, de la simulación por encima del sentido tradicional de lo real, no contaba con objetos verdaderamente representativos. Fredric Jameson ha puesto de manifiesto que el posmodernismo ha minado las epistemologías de la profundidad que existían tras la representación tradicional. La existencia no se refiere a la esencia, lo manifiesto no se refiere a lo latente, el significado no se refiere al significante ${ }^{2}$. Afirmaba Jameson que los objetos que puedan representar este mundo de superficie serán precisamente aquellos que no permiten la representación tradicional. Hoy lo vemos más claro: no hay que recurrir al ámbito de la ficción para hallar los objetos posmodernos, sencillamente existen en el ciberespacio, en los iconos, ventanas y capas de la informática personal, en las simulaciones del ordenador.

En El pensamiento salvaje, Claude Lévi-Strauss (1975) utilizó el término "bricolaje” para referirse al estilo de ciencia asociativa de lo concreto practicada por muchas sociedades no occidentales, en contraste con la metodología analítica tradicional de la ciencia occidental. Hoy, este "bricolaje” triunfa como estilo de aprendizaje en las sociedades de la información: no se aprende a través de largos discursos, sino por mezcla de instantáneas que nuestro cerebro va atrapando al vuelo sobre los múltiples y variados escenarios de la existencia ${ }^{3}$. Por eso, nuestra situación no es definitiva, no estamos situados, sino permanentemente situándonos, buscando y tratando de hallar el paisaje más completo, el plano que nos permita provisionalmente la mejor comprensión posible de la realidad. "Para un sujeto educado en la modernidad, la descodificación del mensaje sigue una línea vertical, pero para el sujeto posmoderno la descodificación se realiza en un plano, dilucidando sin confusión, integradamente, en el abigarramiento sonoro o gráfico que tanto desconcierta al adulto en las discotecas, los conciertos de rock, los nuevos centros comerciales o los videojuegos” (Verdú, 2005, 28). Así, elegimos o rechazamos, construimos nuestra biografía.

Sin cargas ni pesos trascendentes, la cultura en la sociedad de la información es consecuente con su complejidad extensiva y con su formidable velocidad (Augé, 2001). La imparable y creciente influencia de Internet en nuestro mundo constituye un cambio global donde gobierna la velocidad, una dromocracia (Virilio, 1988). La velocidad era algo intrínseco a la idea misma de modernidad, pero la globalización ha ampliado exponencialmente la inmediatez y los medios tecnológicos para lograrla. Sufrimos una extraña sinécdoque informacional, es como si el lema de la cadena televisiva CNN, "slow news, no news” (noticias lentas no son noticias), acaso válido para ciertos ámbitos y voces, se hubiese adueñado de todos los ámbitos, de todas las voces. Hay una íntima relación entre el poder y la velocidad. Donde más poder político y económico existe más poder tiene la velocidad. La Red, donde la información transita a la velocidad de la luz, se nos aparece como la absoluta dromocracia. La velocidad transforma las estructu-

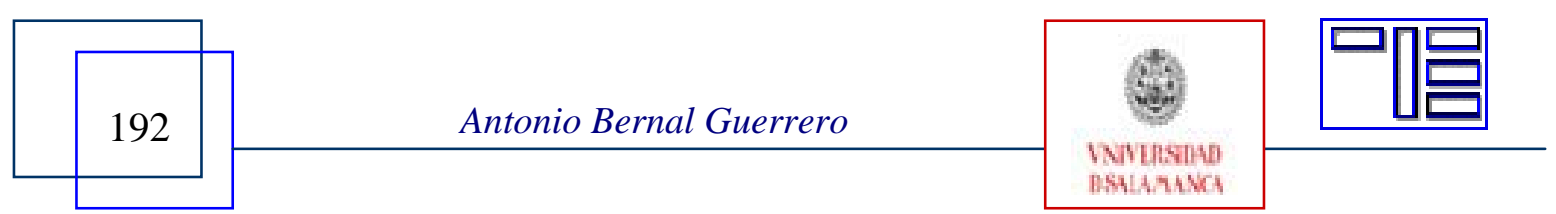


ras de la realidad, se halla presente en todo, su tiranía parece llegar a todas las ramas de la actividad humana (Ramonet, 1998). "Renovarse o morir" ya no es un lema para el cambio profundo y sereno, es una máxima de supervivencia en un mundo sojuzgado por el imperio de la inmediatez (como muestra sirva esta: "Renovarse cada tres minutos o morir” fue el lema de lanzamiento de la página digital del periódico El Mundo). Esta tiranía no sólo afecta al mundo periodístico, piénsese en la investigación científica y la carrera competitiva que sostienen grupos de investigación de todo el mundo por llegar antes a ciertos descubrimientos, patrocinados por empresas que mantienen igualmente una lucha descarnada por conseguir con celeridad posiciones de ventaja en el mercado global. Así mismo, la tecnología informática es un campo de batalla donde los creadores de hardware y de software combaten contrarreloj por tratar de aumentar y mejorar las velocidades de enganche, de acceso, de cifrado de datos, de procesamiento de la información, de compresión de los programas, de selección de páginas, de paso de bits o baudios por segundo, de conversación en los chats, de descarga de software...

Para el mundo anterior, relativo al capitalismo de producción, la lectura era fundamental. Era maestra inagotable, alentadora del cambio, bálsamo para todas las heridas. El libro impreso, independientemente de su valía, siempre era mejor que cualquier otra cosa. Esta sacralización del libro per se pierde todo su sentido en el mundo audiovisual actual, donde legiones de jóvenes descifran reglas y desarrollan nuevas destrezas atrapados por la intriga de los videojuegos, mientras están cambiando su mentalidad frente a la interfaz del ordenador que les exige una interacción continua ${ }^{4}$. El libro, inequívocamente, goza de ventajas sobre los videojuegos: desarrolla el mundo interior de la persona, contribuye a desarrollar la atención y es el mejor medio para la transmisión de cierta información; pero, en la cultura de la simulación, dromocrática, precisamente sus ventajas propician el rechazo o la postergación frente a la mayor facilitación adaptativa de otros artefactos a la cultura de nuestros tiempos "hipermodernos" (Lipovetsky, 2006).

\section{3.- UN DESENCUENTRO CULTURAL}

Conexión y comunicación, propiciadas por las nuevas tecnologías activas e interactivas de la comunicación, hacen posible el paso de la información a la conversación, donde emerge la afectividad de un yo distribuido: "Chatear es multiplicar las sinapsis en la superficie del mundo, y de ahí nace la composición de un yo comunicado/comunitario" (Verdú, 2005, 179). La emergencia de la blogosfera (totalidad de blogs) en Internet, por ejemplo, ha impulsado la participación masiva de la sociedad en la gigantesca conversación digital, en la comunicación humana mediada por las nuevas tecnologías (VV.AA., 2005). Decenas de millones de blogs pueblan la Red, pero cada segundo aparece uno nuevo, y su crecimiento es exponencial, duplicándose el número antes de los seis meses. La cultura blog representa un mecanismo de control y crítica de los medios más convencionales de información y de creación de opinión; pero, al mismo tiempo, supone un modo de expansión, de interferencia, de apelación afectiva, de penetración en la gigantesca trama de la conexión.

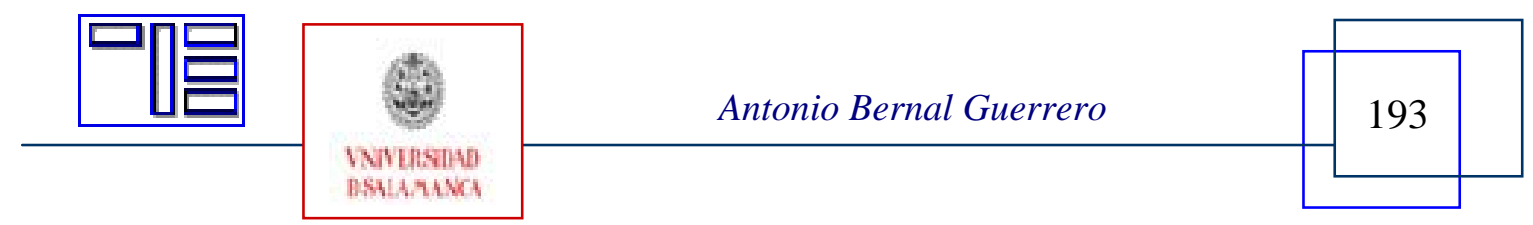


El nuevo escenario geopolítico tras el origen y desarrollo de Internet parece haber agudizado las tensiones entre lo local y lo global (Giddens, 2000). En este sentido, preconiza Negroponte (1997) que los medios de comunicación se agrandan, pero para nutrir a grupos y colectivos cada vez más pequeños, en una espiral de especializaciones dirigida a grupúsculos aún de menor tamaño reunidos en torno a sus preferencias, hallándose al final como única audiencia una sola persona. Éste es el paisaje de la postinformación. No es demasiado extraño que este proceso de diversificación, de atomización, genere en los individuos la necesidad de interactuar, de buscar relación, de hallar cómplices, de encontrar semejantes, amigos (Lévy, 1999). Y la forma que emplea el blogger es a través de la emisión de su subjetividad, mostrando su singularidad al mundo digital, esperando que el resto del globo sintonice con él. La blogosfera es tal vez un modo singular de reivindicación de la gente, desde la comunidad internauta, una forma de reclamar que va más allá de que se cuente con uno, tantas veces restringida a lo meramente cuantitativo, sino de que uno cuente para los demás, un modo de manifestar la propia voz, de no renunciar a sentirse alguien en la orgía de la conexión.

Por lo demás, no se puede adoptar como exclusivo criterio de valoración cultural los índices de lectura. En las sociedades de la información, para valorar el nivel cultural, hay que contar también con otros medios, capaces igualmente de posibilitar conocimiento, instrucción y sentido crítico ${ }^{5}$. No se puede menospreciar el valor cultural que puedan ofrecer los medios audiovisuales, dentro de la sociedad interactiva del consumo. Todas las novedades culturales sufren resistencia: pasó con la fotografía, con el cine, con el cómic, con la televisión... Los jóvenes actuales crecen en plena era digital, para ellos los videojuegos, los videoclips, la publicidad o el net-art constituyen formas de entretenimiento "naturales”, junto al cine, la música, la televisión. Prácticas culturales que están cambiando mentalidades, tal vez generando una nueva era, no necesariamente peor, contrariamente a lo que piensan los agoreros de hoy, que aún no somos capaces de descifrar exitosamente. Sirva, al menos, para desdramatizar algo la denominada crisis de la lectura. La permanencia en la nostalgia oxida la mente. Por eso es conveniente tener sólo la justa.

Como si emergiera de otros tiempos, buena parte del profesorado suele afrontar, en la vida cotidiana de las aulas, el reto de la formación de las nuevas generaciones, el desafío de la transmisión cultural. Instalados en claves culturales de otra época, nuestros alumnos se distancian, se alejan y, en considerable medida, fracasan. Elogiando la lentitud y sobrevalorando la duración, como si el tiempo se hubiera detenido o pudiera detenerse, no pocos profesores se sienten frustrados día a día frente a un auditorio que centrifuga el pasado a la velocidad de la luz, que vive fuera de las aulas entregado al ritmo de la sociedad digital. Muchos de aquéllos se dejan invadir por la nostalgia de un tiempo pretérito que se fue para siempre, sintiéndose víctimas fatales de un cruel destino que les hizo nacer más tarde de lo que hubieran querido, condenándoles a vivir en un mundo fuera del mundo. Realmente, se produce una incomunicación profunda, un desencuentro cultural que terminan padeciendo tanto los docentes como los estudiantes.

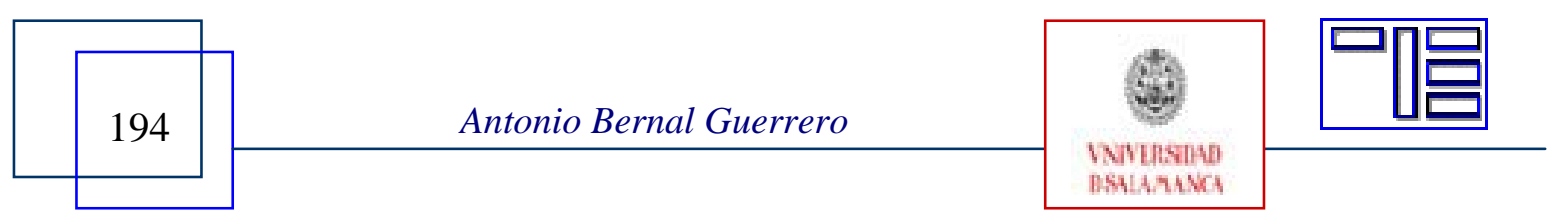


Sucesos e impactos, emociones, nutren al consumidor del siglo XXI, predominan en la consumición de bienes y servicios, de información y comunicación, iluminando de continuo el presente y nublando el pasado. Si se quiere despertar la atención de una población habituada al vértigo de la sociedad de la información, habrá que buscar analogías, metáforas, que arranquen del presente, que partan de sus intereses próximos, más espontáneos, del fluir de su vida emocional. La sociedad digital nos abre, con todas las matizaciones que quieran hacerse, a la lectura del mundo, a reparar en la comprensión cabal de la comunicación humana (García Carrasco, 2007). Si los sistemas educativos actuales ignoran la vigencia de la cultura de la simulación, el desencuentro con las nuevas generaciones estará asegurado.

\section{4.- LA CULTURA DE LA LECTURA EN LOS ESCENARIOS DEL SIGLO XXI}

Las condiciones de las sociedades de la información reclaman un nuevo marco contextual para la cultura de la lectura, ofrecen nuevas posibilidades y demandan lectores de nuevos perfiles. Los sistemas educativos han de cambiar en consonancia con las nuevas circunstancias. Plantearse una nueva cultura organizativa en los sistemas escolares y un cambio en el sentido mismo del currículum parece algo necesario, si se quiere que la lectura forme parte activa de la vida de todos los sujetos. "Resulta paradójico que sea la escuela la que, al encerrar la lectura en sus especializados textos, contribuya a degradar el mismo canon que dice defender” (Gimeno, 2005, 93).

Nunca se había dispuesto de una tecnología tan potente para hacer realidad el ideal ilustrado de que todo el conocimiento acumulado esté disponible para todos. La digitalización de la información (escrita, sonora, visual) podrá hacerlo posible. La desmaterialización de su soporte permite que la información pueda estar disponible en cualquier sitio y en cualquier momento. Se rompen las dificultades de espacio y de tiempo para el transporte y acceso al conocimiento y el almacenamiento de la información apenas ocupa espacio. Además de aprender a manejar los fondos bibliográficos impresos, los lectores-navegantes del siglo XXI exigen el conocimiento de las pautas necesarias para guiarse y poder aventurarse en la lectura electrónica (Poustie, 2000). Precisan desarrollar su competencia lectora en nuevos entornos de aprendizaje.

Las nuevas redes de acceso al conocimiento permiten llevar las bibliotecas y toda la información que circula por el mundo en cualquier momento a cualquier centro, a cualquier aula, a cualquier rincón donde podamos disponer de un ordenador. Colocado frente a su pantalla, el sujeto, sin moverse de su asiento, no encuentra fronteras entre los diferentes tipos de lectura que puede realizar (textos científicos, ensayos, poesía, correo, publicidad, noticias...), sólo sus intereses o necesidades indican el ritmo de la lectura. Las posibilidades educacionales que se abren son muy sugerentes al hilo de la diseminación del texto. ¿Seremos capaces de aprovecharlas?

Se puede continuar afirmando que, frente al fracaso escolar, al escaso éxito de las prácticas lectoras, lo que hace falta es insistir en el valor del esfuerzo y de la disciplina.

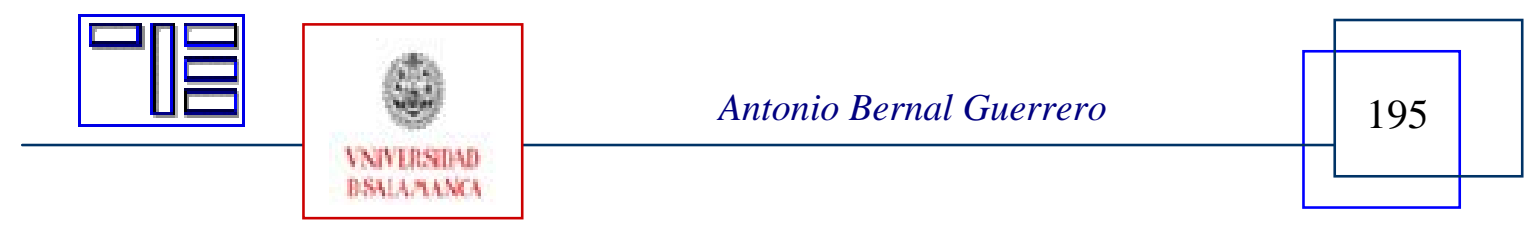


Esta es una vía de análisis que parece insuficiente. Qué duda cabe de que hace falta esforzarse en el aprendizaje de la lectura, como en tantos otros, qué duda cabe de que precisamos disciplina para llevar adelante nuestros quehaceres cotidianos. La cuestión es que estas medidas no parecen calar en los intereses de los estudiantes, probablemente porque se corresponden a otros modelos culturales ya obsoletos, alejados de los nuevos patrones de la cultura del consumo, de la simulación. Pero la "mayoría de las personas, y sobre todo los educadores, se resisten a modificar las prácticas con las que se han formado y con las que se sienten cómodas” (Gardner, 2005, 107). La resistencia a prácticas innovadoras adopta diversas formas: conservadurismo, crítica a los modismos, anticipación imaginaria de riesgos más o menos probables o impotencia para las buenas prácticas. Tratar de vencer las resistencias afrontándolas directamente tal vez no sea el mejor camino; al contrario, puede contribuir a reforzarlas. Un buen modo de afrontarlo es partir de una situación de insatisfacción manifiesta o de frustración evidente para proponer maneras de compensar las insuficiencias percibidas. Se es más receptivo siempre en una situación de manifiesta deficiencia. Este es el caso de la problemática que genera la lectura en los sistemas escolares actuales y en la sociedad misma. Pero, ¿qué sugerir para mejorar las prácticas lectoras en los contextos de las sociedades de la información?

Por de pronto, la interrogante nos remite al lector potencial. Al margen de los medios de que dispongamos, los límites los encontraremos en la capacidad de los sujetos para emprender su andadura lectora y también en el interés que podamos suscitar en ellos para crear el hábito lector. "El verdadero problema de la poca práctica de la lectura parece situarse más en el terreno de los hábitos que en el de los medios (...) Lo más grave es la falta de motivaciones para leer, lo cual no es un problema de medios, sino el síntoma de un déficit cultural y educativo, la existencia de una débil orientación subjetiva hacia la lectura” (Gimeno, 2005, 90). Pero también es cierto que, nunca como ahora, se habían dado condiciones tan patentes para apreciar la lectura como tecnología al servicio del lector, de sus intereses, gracias a la hipertextualidad propiciada por las últimas tecnologías de la información y de la comunicación. La consideración de la lectura como experiencia personal, independientemente de los soportes textuales, fluye fácilmente en los nuevos contextos culturales de la sociedad informatizada.

Todas las finalidades que podamos atribuir al aprendizaje de la lectura (desarrollo del conocimiento, desarrollo del sentido social y del civismo, desarrollo de otras competencias, etc.), encuentran en el desarrollo del potencial personal su punto de inflexión. El desarrollo de la competencia lectora en el siglo XXI pasa por su vinculación real a procesos de personalización significativa. Desarrollar la competencia lectora supone aproximación sin cuento a los lectores potenciales, a cada lector, para suscitar el impulso hacia la lectura. Tal aproximación, igualmente válida para la adquisición de otros aprendizajes educativos, ha de vincularse a la vida emocional de los sujetos, de cada sujeto. Hastiados de ser tratados como objetos y hartos de acumular objetos, los nuevos consumidores, gracias a las posibilidades que ofrecen los últimos medios de comunicación, buscan la conexión, sustancialmente afectiva, la elección, convertirse en emisores

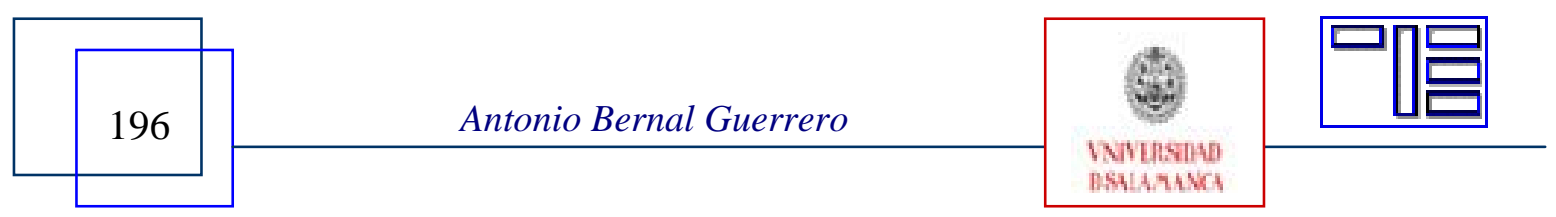


dinámicos dentro de la gran trama de la conexión. El carácter bimodal de nuestra experiencia de aprendizaje (emocional y cognitiva) se abre paso en las nuevas sociedades de la información, de la conversación digital, a la velocidad que circulan los bits por el mundo electrónico. La vinculación de la lectura con los resortes emocionales parece del todo necesaria, prestando atención a la cotidianidad de la vida impregnada de nuestros afectos; pero, al mismo tiempo, lo que tal vez también nos estén desvelando los nuevos contextos de prácticas culturales, sea la necesidad de ligar sin solución de continuidad los beneficios del proceso lector a la comunicación con los otros, a la relación con los semejantes, de cuerpo presente o mediante el palimpsesto digital.

\section{5.- BIBLIOGRAFÍA}

AUGÉ, M. (2001): Ficciones de fin de siglo. Barcelona, Gedisa.

BAUDRILLARD, J. (1984): Cultura y simulacro. Barcelona, Kairós.

BRUNER, J. (2001): Desarrollo cognitivo y educación. Madrid, Morata.

COUPLAND, D. (2006): jPod. Barcelona, El Aleph.

GARCÍA CARRASCO, J. (2007): Leer en la cara y en el mundo. Barcelona, Herder.

GARDNER, H. (2005): Las cinco mentes del futuro. Barcelona, Paidós.

GIDDENS, A. (2000): Un mundo desbocado. Madrid, Taurus.

GIMENO, J. (2005): La educación que aún es posible. Madrid, Morata.

GRAHAM, G. (2000): Internet. Una indagación filosófica. Madrid, Cátedra.

GREENO, J.G., COLLINS, A.M. y RESNICK, L.B. (1996): Cognition and learning, en BERLINER, D.C. y CALFEE, R.C. (eds.). Handbook of Educational Psychology. Nueva York, Simon \& Schuster Macmillan, 15-46.

GUBERN, R. (1987): El simio informatizado. Madrid, Fundesco.

JAMESON, F. (1995): El posmodernismo o la lógica cultural del modernismo avanzado. Barcelona, Paidós.

JONASSEN, D.H. y LAND, S.M. (2000): Theoretical foundations of learning environments. Mahwah, N.J., Lawrence Erlbaum Associates.

LÉVI-STRAUSS, C. (1975): El pensamiento salvaje. México, F.C.E.

LÉVY, P. (1999): ¿Qué es lo virtual? Barcelona, Paidós.

LIPOVETSKY, G. y CHARLES, S. (2006): Los tiempos hipermodernos. Barcelona, Anagrama.

MARINOFF, L. (2006): El ABC de la felicidad. Barcelona, Ediciones B.

MURRAY, J.H. (1999): Hamlet en la holocubierta. Barcelona, Paidós.

NEGROPONTE, N. (1997): El mundo digital. Barcelona, Ediciones B.

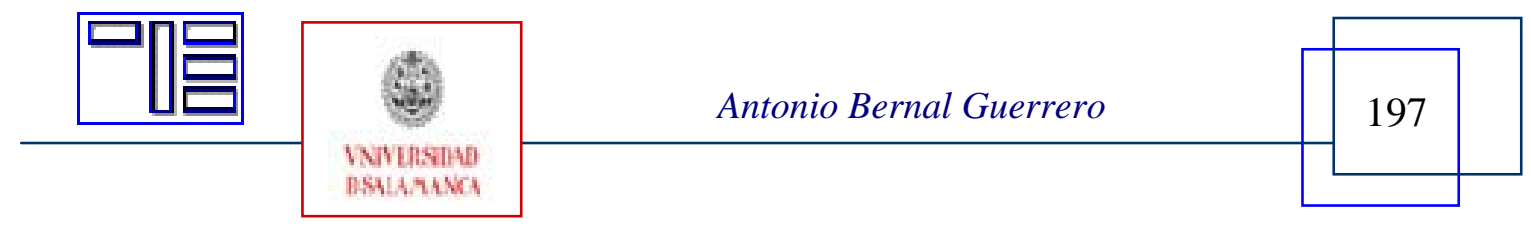


Revista Electrónica Teoría de la Educación.

Educación y Cultura en la Sociedad de la Información.

http://www.usal.es/teoriaeducacion

Vol. 9. No 3. Noviembre 2008

OCDE (2007): El Programa para la Evaluación Internacional de Alumnos de la OCDE (PISA 2006). Informe Español. Madrid, Secretaría General Técnica del MEC. (www.cnice.mec.es).

PINAR, W.F. (ed.) (1998): Curriculum. Toward new identities. Nueva York, Londres: Garland Publishing, Inc.

POUSTIE, K. (2000): Un centro de conocimiento para la comunidad, una nueva función para la biblioteca pública. Barcelona, Fundación Bertelmann.

RAMONET, I. (ed.) (1998): Internet, el mundo que llega. Madrid, Alianza Ed.

SARTORI, G. (1998): Homo videns. La sociedad teledirigida. Madrid: Taurus.

TOURIÑÁN, J.M. (dir.) (2005): Educación electrónica. El reto de la sociedad digital en la escuela. Santiago de Compostela, Xunta de Galicia.

TURKLE, S. (1997): La vida en la pantalla. Barcelona, Paidós.

VERDÚ, V. (2005): Yo y tú, objetos de lujo. Barcelona, Mondadori.

VIRILIO, P. (1988): La estética de la desaparición. Barcelona, Anagrama.

VOUILLAMOZ, N. (2000): Literatura e hipermedia. Barcelona, Paidós.

VV.AA. (2005): Blogs. La conversación en Internet que está revolucionando medios, empresa y a ciudadanos. Madrid, ESIC.

\section{Notas}

${ }^{1}$ El último Informe Español PISA 2006, dentro del Programa para la Evaluación Internacional de Alumnos de la OCDE es contundente al respecto. Los resultados globales en comprensión lectora indican que se ha producido un descenso general en todos los países, que es muy notable en el promedio español: 461 puntos, 10 puntos por encima del Total Internacional, pero 23 por debajo del Total OCDE y 31 por debajo del Promedio OCDE. Dice textualmente el mencionado Informe: "Este resultado español en comprensión lectora es francamente preocupante y confirma el resultado español también pobre en comparación con los de los países de nuestro entorno en el estudio de la IEA, PIRLS, que valora la comprensión lectora a los 9 años ( $4^{\circ}$ de primaria)" (OCDE, 2007, 69). Por eso, se recomienda que la lectura y la mejora de la comprensión lectora de los alumnos españoles debiera convertirse en un objetivo del conjunto de la sociedad, en el que se impliquen, además de las autoridades y los agentes educativos, las familias, las instituciones y los medios de comunicación.

${ }^{2}$ La idea misma de autoría literaria se ha transformado con el cambio cultural. Como ya advirtiera Sherry Turkle (1997) hace una década, con las últimas tecnologías de la información y de la comunicación se ha hecho más verosímil que nunca el sujeto vacío, el "yo" como constructo lingüístico, tal como preconizaron, durante los años sesenta y setenta, Barthes, Derrida, Foucault, Deleuze, etc. Bajo sus auspicios, la idea de autor, de creador "original" ha entrado en crisis; para no pocos, se ha convertido incluso en un anacronismo dentro del panorama literario actual. La identidad de la autoría se desdibuja (Vouillamoz, 2000). La disolución del yo y la destrucción de la autoría han desembocado en una literatura descentrada en la autoría y descentrada en la trama. Las obras lineales dan paso a narraciones complejas, sin centro preciso, en las que todas las perspectivas posibles tienen su lugar, pudiéndose originar innumerables desarrollos. La fragmentación, el abandono de la linealidad narrativa y la multiformidad son las cualidades primordiales de la nueva literatura (Murray, 1999). Se trate de una sofisticación del nuevo pensamiento literario, se trate de un reflejo de la sentida y aun compulsiva preocupación de la sociedad actual por las múltiples posibilidades de vida, las diversas versiones de la realidad forman parte de nuestro modo de pensar y vivir en el mundo de hoy. Con la relevancia de la aleatoriedad en el desarrollo narrativo, crece la

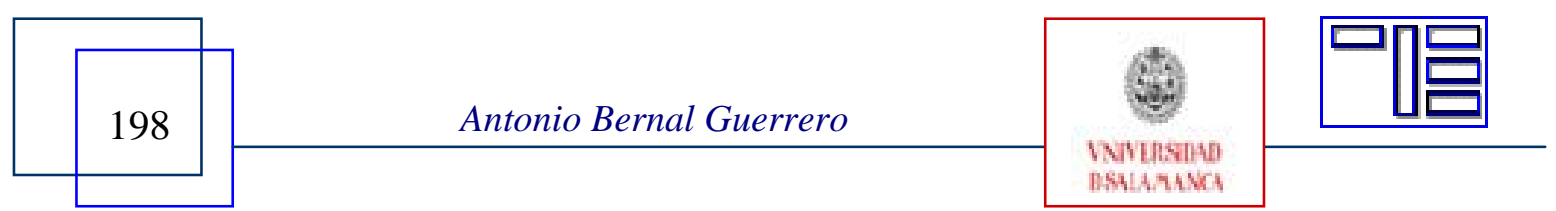


importancia de las computadoras. Así, encontramos creaciones cibernéticas al estilo de la novela jPod, de Douglas Coupland (2006), donde se aprecian las posibilidades combinatorias y recombinatorias que ofrecen las máquinas; literatura que podríamos calificar de "asistida” por ordenador.

${ }^{3}$ Señala Verdú (2005) que ser sabio hoy equivale a contar con un amplio punto de vista a partir del cual se dirime y se elige el bien sobre un plano, fotografiándolo. A modo de ejemplo, refiere el viaducto francés de Millau diseñado por Norman Foster e inaugurado en 2004, que se encuentra a 245 metros del suelo, resite vientos de $210 \mathrm{kms}$. y que costó más de 400 millones de euros. Su idea original no fue la ingeniería propiamente, sino la visión paisajística, la emoción de ver la naturaleza desde la propia perspectiva, sin teorías, directamente, empáticamente.

4 A diferencia de Sartori (1998), que asocia el triunfo de la tecnología a la pasividad contemplativa y confortable del usuario, reflejado paradigmáticamente en el espectador televisivo, el homo videns, no vemos en la interactividad que aportan las nuevas tecnologías multimedia y la realidad virtual el fin del mundo digital. Al contrario, quizás esta posibilidad misma ha propiciado su innegable éxito. Un mundo, sin embargo, que dificulta el pensamiento, la capacidad reflexiva, la atención, puede amparar puntos de vista nada alentadores para el porvenir de nuestra especie. Así, Román Gubern (1987) ha manifestado que nos encaminamos hacia el regreso evolutivo en lugar del progreso. Para Gubern, esta reversión de la dirección del tiempo nos conduce de nuevo al mono, bueno, al “mono sapiens”, al "simio informatizado".

5 Para la tradición cultural escrita, formar lectores, buenos lectores, constituye un modelo educativo coherente con un proyecto cultural que estima que lo que permanece escrito, lo guardado, es lo más valioso que puede ponerse a disposición de los demás. La cultura impresa, aquella que puede leerse, ha configurado por completo el currículum, reverenciada por una enseñanza basada exclusivamente en ella, extendiéndose la idea de que sólo de aquello sobre lo que se escribe debe ocuparse la cultura prestigiosa, la cultura “culta”.

Para citar la presente editorial puede utilizar la siguiente referencia:

BERNAL GUERRERO, Antonio (2008). Cambio cultural y lectura. Hacia una nueva cultura lectora. En SÁNCHEZ i PERIS, Francesc J. (Coord.) Videojuegos: una herramienta educativa del "homo digitalis" [monográfico en línea]. Revista Electrónica Teoría de la Educación: Educación y Cultura en la Sociedad de la Información. Vol. 9, nº 3. Universidad de Salamanca [Fecha de consulta: dd/mm/aaaa]. http://www.usal.es/ teoriaeducacion/rev_numero_09_03/n9_03_bernal.pdf ISSN: 1138-9737

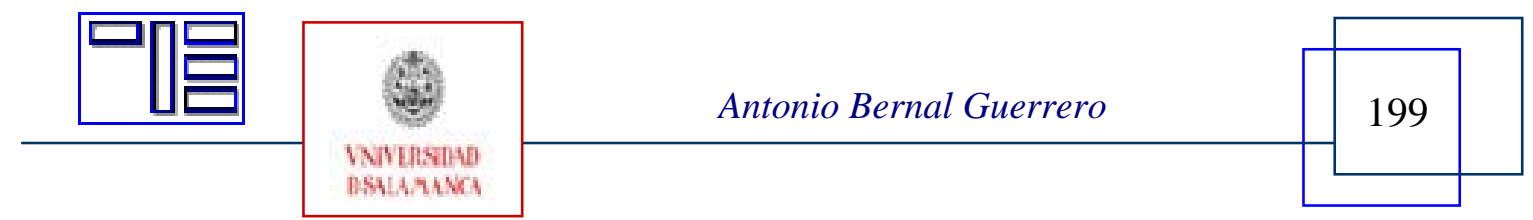

